\title{
A Cross-sectional Investigation of Latrine and Pure Water Coverage and Related Factors Among Residence of Negele town, Arsi zone, Southeast Ethiopia
}

\section{Diriba Temesgen Dagaga ( $\nabla$ direteme@gmail.com )}

Madda Walabu University, College of Natural and Computational Sciences, Department of Biology, Bale Robe, Ethiopia https://orcid.org/0000-0001-7034-7331

\section{Girma Deboch Geleta}

Negele College Preparatory High School

\section{Research article}

Keywords: Associated factors, Ethiopia, Negele town, latrine coverage, pure water coverage

Posted Date: September 8th, 2020

DOl: https://doi.org/10.21203/rs.3.rs-59656/v1

License: (c) (1) This work is licensed under a Creative Commons Attribution 4.0 International License.

Read Full License 


\section{Abstract}

\section{Background}

Access to safe water and improved sanitation contributes to the human heath and socio-economic development of a country. This study was conducted to assess the latrine and pure water coverage and related factors among dwellers of Negele town, Arsi zone, southeast Ethiopia

\section{Method}

Two kebeles (administrative units) were randomly selected from each zone of the town to collect data via questionnaires from randomly selected households (380), via interview from purposely selected key informants (40) and via personal observation employing a cross-sectional survey design from April-May 2018. Data were analyzed using microsoft Excel program and the results were expressed using table as frequencie and percentages .

\section{Result}

Latrine coverage of the town was low (45\%) mainly due to shortage of land and fund. Among the available latrines, $75 \%$ were closer than recommended distance $(6 \mathrm{~m})$ to kitchens, $52.3 \%$ lacked roofs, $53 \%$ lacked doors, and $100 \%$ lacked hole cover and water to clean. Latrine lacking households defecate in various sites of the environment with problems on environmental sanitation, personal safety and health issues. Similarly, pure water coverage was very low (7.6\%) as a result of deficient water sources and nonfunctioning pipe lines forcing the people to use unprotected water source or expend much time in fetching water from private taps.

\section{Conclusion}

Latrine and pure water coverage of Negele town was far less than the national Millennium Development Goal (MDG) which targetted $100 \%$ improved hygiene and sanitation coverage by 2015 . The big gap demonstrated by this study may intiate the admistration of the town to provide land, arrange loan or search for aids for the construction of standardized private and public toilets. Searching additional water sources like underground water and maintaining non-functional and/or constructing new pipe lines may also be promoted as a result of this study to improve the pure water coverage of the town. Public participatory plans may also be designed to solve shortage of latrine and water coverage of the town via continuous awareness creation.

\section{Background}

Access to potable water and sanitation facilities like latrine is a basic human right and is related to social and psychological well-being, public health, socio economic development and environmental sustainability [1]. However, millions of people living in developing countries faile to access such facilities due to fast population growth, poor service provision,, poor economic and educational status. They are 
forced to practice open defection, expend lots of time and energy in fetching water and to suffer from and die of wide ranges of preventable diseases.

Open defecation has been commonly practiced through out Ethiopia, for instance by 28 million people in 2015 , due to lack of hygiene awareness, adequate policy and income [2]. Sanitation coverage of the country was about $71 \%$ in 2015 and approximately, $42 \%$ of the Ethiopians lacked access to safe water in 2017 [3] though the country targetted 100\% improved hygiene and sanitation coverage by 2015 ; extension of safe water supply to $98 \%$ and $100 \%$ of rural and city dwellers by 2020 via WASH program [4]. Open defecation and lack of access to safe water might have contributed to the wide prevalence of common water borne diseases, and some recently emerged life threatening Acute Watery Diarrhea (48 814 cases and 880 deaths in 2017; [5] and cholera (614 cases, [6]) in the country..

Urban expansion with continuous inflow of population from rural areas can lead to constraints on the supply of potable water and sanitary services. Scientific inquiry is necessary to determine the potable water and latrine coverage of an area so as to predict the environmental and population health risks and implement appropriate measures. Such studies have been conducted in some parts of Ethiopia. [7] reported a 58.4\% latrine coverage for Bahir Dar Zuria District, north western Ethiopia. [8] also reported that about $68 \%$ and $95 \%$ of the inhabitants of Wolaita Sodo Town (Southern Ethiopia) had access to improved water supply and latrine, respectively. According to [19], 31.2\% of respondents of Gonji Kolela Woreda in West Gojjam Zone, northwestern Ethiopia were using either river or unprotected spring for their domestic consumption [9] indicated the possession of latrine by $89 \%$ of households in Diretiyara, Eastern Ethiopia. Similarly, [10] reported latrine coverage of $27.5 \%$ for Chiro Zuria Woreda, eastern Ethiopia

This research was conducted at Negele town, south east Ethiopia, which was established on the landscape of 300 hectares in 1984. A portion of its residents have access to latrine and pure water whereas others practice open defecation and use unsafe water sources. However, no study has been done to assess the pure water and latrine coverage of the town. Thus, this study was initiated to determine the pure water and latrine coverage, and associated factors of the town so as to contribute to future efforts to achieve the national goals of the country in providing access to improved sanitation and water supply. Since the only source of water considered as "pure" encountered in the study was tap water, tap water and pure water are used interchangabily in this paper.

\section{Methods}

\subsection{Description of the Study Area}

This research was conducted at Negele town, located in Arsi zone of Oromia region, southeast Ethiopia $\left(7^{\circ} 21^{\prime} \mathrm{N} 38^{\circ} 42^{\prime} \mathrm{E}\right)$. The town was established on the landscape of 300 hectares in 1984. It is located 204 $\mathrm{km}$ away from Addis Ababa, the capital city of Ethiopia. Negele town expriences mild climate with annual temperature and rain fall ranging from $12-23^{\circ} \mathrm{Cand} 7000-1300 \mathrm{~mm}$, respectivel. The population size of the town was 21,478 in 2017 . Negele town has started to be administered at municipality level since 2000 
and has its own administrative structure led by mayor. The town is demarcated by different rural kebeles (the lowest administrative unit in Ethiopian): Amuma-Arago in the east, Nano Jawi in the west, Nano Hecho in the north and Cire Anole in the south. It has a primary school, a Secondary School and one health centre. The economic activity of the surrounding of the town is predominantly agriculture comprising farming and cattle breeding.

\subsection{Study design and population sampling}

A community-based cross-sectional qualitative and quantitative descriptive survey was conducted in Negele town from April 01 to May 31, 2018. The study targeted 4095 households (2631 males and 1464 females) out of the 22,578 total population of the town during the study period..

Table 1

Study villages with their corresponding zones and population sample size of Negele town during the study

\begin{tabular}{|c|c|c|c|c|c|c|c|c|}
\hline \multirow[t]{3}{*}{ № } & \multirow[t]{3}{*}{ Zones } & \multirow{3}{*}{$\begin{array}{l}\text { Target } \\
\text { populations }\end{array}$} & \multirow{3}{*}{$\begin{array}{l}\text { Selected } \\
\text { villages }\end{array}$} & \multirow{3}{*}{$\begin{array}{l}\text { Total target } \\
\text { populations }\end{array}$} & \multicolumn{4}{|c|}{ Sample sizes $(n=406)$} \\
\hline & & & & & \multicolumn{2}{|c|}{ Frequency } & \multirow[t]{2}{*}{ Total } & \multirow[t]{2}{*}{$\%$} \\
\hline & & & & & Female & Male & & \\
\hline \multirow[t]{2}{*}{1} & \multirow[t]{2}{*}{ Central } & \multirow[t]{2}{*}{1718} & $\begin{array}{l}\text { Center of } \\
\text { town }\end{array}$ & 590 & 34 & 54 & 88 & 21.67 \\
\hline & & & $\begin{array}{l}\text { Center of } \\
\text { FTC }\end{array}$ & 555 & 36 & 46 & 83 & 20.4 \\
\hline \multirow[t]{2}{*}{2} & \multirow[t]{2}{*}{ Eastern } & \multirow[t]{2}{*}{1353} & Sheep site & 382 & 23 & 34 & 57 & 14 \\
\hline & & & Najate & 520 & 30 & 47 & 77 & 18.96 \\
\hline \multirow[t]{2}{*}{3} & \multirow[t]{2}{*}{ Western } & \multirow[t]{2}{*}{1024} & $\begin{array}{l}\text { Western } \\
\text { Hindy }\end{array}$ & 417 & 24 & 38 & 62 & 15.27 \\
\hline & & & $\begin{array}{l}\text { Mosque } \\
\text { area }\end{array}$ & 265 & 15 & 25 & 39 & 9.6 \\
\hline Total & 3 & 4095 & 6 & 2729 & 162 & 244 & 406 & $100 \%$ \\
\hline
\end{tabular}

\section{3. Data Gathering Tools and Procedures}

A preliminary survey was conducted prior to the actual study from March 24-30, 2018 to sketch out the overall status of latrine and pure water coverage. Observation, interview and questionnaire were used as data gathering tools. [22] was referred in the preparation of some points in observation check lists and some questions in questionnaire and interview (See Accessary file 1, 2 and 3), but they were mostly prepared by the authors based on the prevailing conditions, community practices and the public available resources and information. 
Latrines were observed for the presence of doors, roofs, hole covers and water supply during households' filling questionnaires according to the prepared observational check list. Fetching of non-tapwater sources (river) and private tapes had been observed. Various fields were also observed for open defecation and sanitation.

Structured questionnaire was administered to gather data related to the households' socio-demographic characteristics, occupation, educational level, source of water, presence or absence of latrines, latrine door, hole cover and roof, where they defecate and what problems they have faced incase they lacked latrine, for the presence of anybody who advised them to construct larine, whether they have a plan to construct latrine in the near future, the number of people using a toilet, distance of toilet from kitchen, availability of water to clean the toilet and sewerage service to clean toilet, measure (s) taken when latrine became full, source of water, treatment(s) undertaken for non-tap water before drinking and exposure to waterborne diseases. Interview was held with 40 purposively selected key informants (head of administration of town, Kebele officials, water and health sector workers) regarding their sociodemography, presence of public toilet, factors affecting latrine and pure water coverage, consequences of latrine shortage, presence of plan and its target to improve the latrine and pure water coverage of the town. As a key informant, the chief administration of the town was also requested for any relevant additional information to add. Questions were prepared in Engish and translated into local language (Afaan Oromo). Necessary orientation was provided to facilitate the process of filling out the questionnaire or responding to the interview questions. Questions were presented in exactly the same wording and in the same order to all participants

\subsection{Data validity and analysis}

Collected data were checked for completeness or errors and analyzed using microsoft Excel program Results were presented in the form frequency and percentage using tables. To test the validity, questionnaires were tested on 25 purposely selected potential respondents (19 males and 6 females) and the revised version was dispatched for the sampled population

\section{Results}

\subsection{Demographic Characteristics of household respondents}

Out of the 406, 380 (93.6\%) households properly filled and retuned the questionnaires. Most of them were young (18-30), muslims (86\%) and married (68\%.). Regarding the educational status (Table 2), 118 (31.05\%) respondents had never attended formal education whereas $186(51.6 \%)$ and $44(11.57 \%)$ respondents had attended primary (grade 1-8) and Secondary level (grade 9-12).. Only $22(5.78 \%)$ of the respondents completed secondary school (grade 12). The majority of the household respondents (277; $59.7 \%)$ had up to 4 family members whereas $108(28.4 \%)$ and $45(11.8 \%)$ of them had $5-10$ and over 10 
family size, respectively. The respondents have engaged in different types jobs, predominantly farmers and merchants 
Table 2

Demographic Characteristics of Household Respondents ( $\mathrm{n}=$ 380)

\begin{tabular}{|c|c|c|c|c|}
\hline \multirow[t]{2}{*}{ variable } & \multicolumn{3}{|c|}{ Frequency } & \multirow[t]{2}{*}{ percent } \\
\hline & Female & Male & Total & \\
\hline Centeral & 68 & 98 & 166 & 43.7 \\
\hline \multicolumn{5}{|l|}{ Administration zones } \\
\hline Eastern & 45 & 81 & 126 & 33.2 \\
\hline Western & 25 & 63 & 88 & 23.2 \\
\hline \multicolumn{5}{|l|}{ Age } \\
\hline $18-30$ & 68 & 57 & 188 & 49.5 \\
\hline $31-40$ & 45 & 63 & 141 & 37.1 \\
\hline $41-80$ & 25 & 22 & 51 & 13.4 \\
\hline \multicolumn{5}{|l|}{ Religion } \\
\hline Christian & 28 & 40 & 53 & 13.9 \\
\hline Muslim & 110 & 202 & 327 & 86.1 \\
\hline \multicolumn{5}{|l|}{ Educational status } \\
\hline No formal education & 41 & 77 & 118 & 31.05 \\
\hline primary $(1-8)$ & 66 & 130 & 196 & 51.56 \\
\hline Secondary $(9-12)$ & 19 & 25 & 44 & 11.57 \\
\hline$>$ Grade 12 & 12 & 10 & 22 & 5.78 \\
\hline \multicolumn{5}{|l|}{ Marital status } \\
\hline Single & 27 & 73 & 100 & 26.3 \\
\hline Married & 111 & 149 & 260 & 68.4 \\
\hline Widow & - & 20 & 20 & 5.26 \\
\hline Divorced & - & - & - & - \\
\hline \multicolumn{5}{|l|}{ Family size } \\
\hline $1-4$ & 90 & 137 & 227 & 59.7 \\
\hline $5-10$ & 26 & 82 & 108 & 28.42 \\
\hline$>10$ & 22 & 23 & 45 & 11.84 \\
\hline
\end{tabular}




\begin{tabular}{|c|c|c|c|c|}
\hline \multirow[t]{2}{*}{ variable } & \multicolumn{3}{|c|}{ Frequency } & \multirow[t]{2}{*}{ percent } \\
\hline & Female & Male & Total & \\
\hline \multicolumn{5}{|l|}{ Occupation } \\
\hline Farmer & 59 & 117 & 176 & 46.3 \\
\hline Merchant & 29 & 91 & 120 & 31.57 \\
\hline Government employee & 28 & 13 & 41 & 10.78 \\
\hline Daily laborer & 14 & - & 14 & 3.7 \\
\hline Other & 8 & 21 & 29 & 7.63 \\
\hline
\end{tabular}

Only $45.3 \%$ of the household respondents indicated that they had latrine (Table 3 ). Latrine coverage was lesser for Eastern zone of the town compared to centeral and western zones. Moreover, over $60 \%$ of respondents who had latrine indicated that a latrine was used by more than 5 people.

The majority of the available toilets were built without skill and technology lacking associated facilities (Fig. 2). Fifty seven (33.13\%), 54 (31.4\%), 18 (10.47\%) and 43 (25\%) of latrine owning households said that their latrines are 3-5m, 2-3m, $6 \mathrm{~m}$ and greater than $6 \mathrm{~m}$ away from kitchens, respectively.

More than half $(52.3 \%)$ of the households replied that their latrine lacked roofs. Roughly, $50 \%$ of households from the Central or Western zones indicated the presence of latrine roofs whereas only $38 \%$ Eastern zone house holds indicated the presence of latrine roofs. Fifty three percent and $100 \%$ of the households indicated the absence of latrine doors and hole cover, respectively.(Table 3) 
Table 3

Responses of households of Negele town regarding latrine coverage and associated facilities.

\begin{tabular}{|c|c|c|c|c|c|}
\hline \multirow[t]{2}{*}{ Variable } & \multicolumn{3}{|c|}{$\begin{array}{l}\text { Zones of Respondents }(n= \\
380)\end{array}$} & \multirow[t]{2}{*}{ Total } & \multirow[t]{2}{*}{$\%$} \\
\hline & Center & East & West & & \\
\hline \multicolumn{6}{|c|}{ Presence of latrine } \\
\hline Yes & 82 & 40 & 50 & 172 & 45.3 \\
\hline No & 84 & 86 & 38 & 208 & 54.7 \\
\hline \multicolumn{6}{|c|}{ Number of latrine users } \\
\hline $1-5$ & 33 & 12 & 20 & 65 & 37.8 \\
\hline $6-10$ & 30 & 8 & 20 & 58 & 33.7 \\
\hline Greater than 10 & 19 & 20 & 10 & 49 & 28.5 \\
\hline \multicolumn{6}{|c|}{ Distance of latrine from kitchen (m) } \\
\hline $2-3$ & 27 & 11 & 16 & 54 & 31.4 \\
\hline $3-5$ & 28 & 17 & 12 & 57 & 33.1 \\
\hline 6 & 9 & 5 & 4 & 18 & 10.5 \\
\hline greater than 6 & 18 & 7 & 18 & 43 & 25 \\
\hline \multicolumn{6}{|c|}{ Presence of latrine roof } \\
\hline Yes & 41 & 15 & 26 & 82 & 47.7 \\
\hline No & 41 & 25 & 24 & 90 & 52.9 \\
\hline \multicolumn{6}{|c|}{ Presence of latrine door } \\
\hline Yes & 39 & 24 & 18 & 81 & 47.1 \\
\hline No & 43 & 16 & 32 & 91 & 52.9 \\
\hline \multicolumn{6}{|c|}{ Presence of latrine hole cover } \\
\hline Yes & - & - & - & - & - \\
\hline No & 82 & 40 & 50 & 172 & 100 \\
\hline \multicolumn{6}{|c|}{ Presence of water for cleaning latrine } \\
\hline Yes & - & - & - & - & - \\
\hline No & 82 & 40 & 50 & 172 & 100 \\
\hline
\end{tabular}




\begin{tabular}{|c|c|c|c|c|c|}
\hline \multirow[t]{2}{*}{ Variable } & \multicolumn{3}{|c|}{$\begin{array}{l}\text { Zones of Respondents }(n= \\
380)\end{array}$} & \multirow[t]{2}{*}{ Total } & \multirow[t]{2}{*}{$\%$} \\
\hline & Center & East & West & & \\
\hline Yes & - & - & - & - & - \\
\hline No & 82 & 40 & 50 & 172 & 100 \\
\hline \multicolumn{6}{|c|}{$\begin{array}{l}\text { Whether latrine became full and overflown earlier or } \\
\text { not }\end{array}$} \\
\hline Yes & 36 & 9 & 12 & 57 & 33.1 \\
\hline No & 46 & 31 & 38 & 115 & 66.9 \\
\hline \multicolumn{6}{|c|}{ Measures taken when latrine was full } \\
\hline Digging new toilet & 65 & 20 & 36 & 121 & 70.3 \\
\hline Drainage to Environment & 17 & 20 & 14 & 51 & 29.7 \\
\hline \multicolumn{6}{|l|}{ Perception of one's own latrine } \\
\hline Clean and good for health & 5 & - & 1 & 6 & 3.48 \\
\hline Dirty and unsuitable for health & 77 & 40 & 49 & 166 & 96.5 \\
\hline
\end{tabular}

The entire latrine possessing households pointed out the lack of water to clean their latrine and sewerage service to clean their latrines when they became full. The lack of sewerage service to clean full toilets had also forced the respondents to dig new toilets $(70 \%)$ or drain to the environment (30\%) (Table 3 ). Moreover, only $6(3.48 \%)$ larine owening households perceived their latrines as clean and good for healthincontrast 166 ( $96.51 \%$ ) that onsidered their latrines as unclean, usually dirty and unsuitable for health. Personal observations support the latter view as indicated in Figure.2.

\subsection{Absence of latrine and associated factors}

Shorteg of income and land were the reasons raised by the majority of households for lacking latrine (Table 4). Latrine lackeing households were used to defecte in open fields $(56 ; 26.92 \%)$, in bush $(54 ; 26 \%)$, in house compound $(80 ; 38.5 \%)$ or in any places as needed $(18 ; 8.65 \%)$ (Fig. 3 ) as there were no public toilets as an alternate. About $50 \%$ of the households replied that they had been advised to construct toilets either by health extension workers or local leader (Table 4). 
Table 4

Responses of households $(n=208)$ who lacked latrine prior to and during the study period regarding kack of latrine and associated factors

\begin{tabular}{|c|c|c|c|c|c|}
\hline \multirow[t]{2}{*}{ Variable } & \multicolumn{3}{|c|}{ Zones of respondents $(n=208)$} & \multirow[t]{2}{*}{ Total } & \multirow[t]{2}{*}{$\%$} \\
\hline & Center & East & West & & \\
\hline \multicolumn{6}{|l|}{ Defecation areas } \\
\hline open space & 20 & 26 & 10 & 56 & 26.9 \\
\hline public toilet & - & - & - & - & - \\
\hline in bush & 16 & 29 & 9 & 54 & 26 \\
\hline in house compound & 42 & 22 & 16 & 80 & 38.5 \\
\hline any place as needed & 6 & 9 & 3 & 18 & 8.65 \\
\hline \multicolumn{6}{|l|}{ Reasons for lack of latrine } \\
\hline no knowing the importance of latrine & - & - & - & - & - \\
\hline lack of enough land & 41 & 35 & 18 & 94 & 45.2 \\
\hline lack of enough money & 36 & 37 & 12 & 85 & 40.8 \\
\hline other & 7 & 14 & 8 & 29 & 13.9 \\
\hline \multicolumn{6}{|l|}{ Problems faced due to lack of latrine } \\
\hline lack of safety & 21 & 25 & 14 & 60 & 28.8 \\
\hline Infectious disease & 12 & 31 & 9 & 52 & 25 \\
\hline pollution of living area & 32 & 13 & 6 & 51 & 24.5 \\
\hline moving out in darkness & 19 & 17 & 9 & 45 & 21.63 \\
\hline \multicolumn{6}{|l|}{ Person advised to construct latrine } \\
\hline health extension & 17 & 27 & 18 & 62 & 29.8 \\
\hline local leader & 23 & 13 & 5 & 41 & 19.7 \\
\hline no body & 44 & 46 & 15 & 105 & 50.5 \\
\hline \multicolumn{6}{|l|}{ Having plan to contact latrine } \\
\hline Yes & 34 & 25 & 9 & 68 & 32.7 \\
\hline No & 50 & 61 & 29 & 140 & 67.3 \\
\hline
\end{tabular}

Most of the houses in the town were built on small plots of land without following the plan of the town and extra area to construct latrine. Latrine lacking households expressed that they were suffering from lack of safety, from illness, pollution of living area and moving out in dark for defection. However, $67 \%$ of 
toilet lacking participants lacked plan to construct latrines in the near future due to income, land or information constraints as expressed earlier.

\subsection{Pure drinking water coverage and associated conditions}

Only 29 households, all from the Central zone of the town, replied that they had their of pure water source (tap water) (Table 5). Few tap water lacking households said that they were using others tap water expending much of their time lining up and their energy in carrying long distance (Fig. 4 ) whereas the majority of them replied that they were using unprotected water sources including ponds and river; specifically Nano River travelling 3 to $5 \mathrm{~km}$ to the north direction of the town (Fig. 4A, B and D). The area of the Nano River is mountainous and creates fetching water it difficult.

Moreover, using river directly for drinking could have been created health problems as $72.6 \%$ of the respondents replied that they directly use non-tap water without boiling or chemical treatment (Table 5). Forty five percent of the households said the have no Knowledge about the effect of impure water on health, but $51 \%$ of them said they or their families had contracted waterborne diseases. 
Table 5

Pure drinking water (Tap water) coverage and related conditions in Negele town in 2018

\begin{tabular}{|c|c|c|c|c|c|}
\hline \multirow[t]{2}{*}{ Variable } & \multicolumn{3}{|c|}{ Zone of respondents $(n=380)$} & \multirow[t]{2}{*}{ Total } & \multirow[t]{2}{*}{$\%$} \\
\hline & Centeral & Eastern & Western & & \\
\hline \multicolumn{6}{|l|}{ Having pure/tap water } \\
\hline Yes & 29 & - & - & 29 & 7.6 \\
\hline No & 137 & 126 & 88 & 351 & 92.4 \\
\hline \multicolumn{6}{|c|}{ Source of water if no tap water } \\
\hline Private tap & 39 & 13 & 4 & 56 & 16 \\
\hline Nano River & 72 & 83 & 58 & 213 & 60.7 \\
\hline Pond and rain & 26 & 30 & 26 & 82 & 23.4 \\
\hline \multicolumn{6}{|c|}{ Using protected non-tap water } \\
\hline Yes & - & - & - & - & - \\
\hline No & 137 & 126 & 88 & 351 & 100 \\
\hline \multicolumn{6}{|c|}{ Treating non-tap water before deinking } \\
\hline Yes, using chemicals & 15 & 3 & 3 & 21 & 6 \\
\hline \multicolumn{6}{|l|}{ like"Bishangari or } \\
\hline \multicolumn{6}{|l|}{ "wuhagar" } \\
\hline Yes, boiling & 28 & 26 & 21 & 75 & 21.4 \\
\hline No & 94 & 97 & 64 & 255 & 72.6 \\
\hline \multicolumn{6}{|c|}{ Knowledge of effect of impure water on health } \\
\hline Yes & 82 & 56 & 55 & 193 & 55 \\
\hline No & 55 & 70 & 33 & 158 & 45 \\
\hline \multicolumn{6}{|c|}{$\begin{array}{l}\text { Self or family member exposed to waterborne } \\
\text { disease }\end{array}$} \\
\hline Yes & 60 & 67 & 53 & 180 & 51.3 \\
\hline No & 77 & 59 & 35 & 171 & 48.7 \\
\hline
\end{tabular}

\subsection{Key informant interview}

Forty key informants with socio-demographic features indicated in Table 6 were properly interviewd. Most of the key informants were males, musilims, married and diploma holders within age range of 18-40. 
Table 6

Demographic features of the key informants

\begin{tabular}{|c|c|c|c|c|}
\hline \multirow[t]{2}{*}{ Variable } & \multicolumn{4}{|l|}{ Occupation } \\
\hline & $\begin{array}{l}\text { Head of town } \\
\text { Administration }\end{array}$ & $\begin{array}{l}\text { Kebele } \\
\text { official }\end{array}$ & $\begin{array}{l}\text { Water sector } \\
\text { workers }\end{array}$ & $\begin{array}{l}\text { Health } \\
\text { workers }\end{array}$ \\
\hline \multicolumn{5}{|l|}{ Sex } \\
\hline M & 8 & 5 & 3 & 18 \\
\hline $\mathrm{F}$ & 1 & - & - & 5 \\
\hline \multicolumn{5}{|l|}{ Age } \\
\hline $18-40$ & 7 & 3 & 3 & 21 \\
\hline $41-60$ & 2 & 2 & - & 2 \\
\hline $61-80$ & - & - & - & - \\
\hline \multicolumn{5}{|l|}{ Religion } \\
\hline Muslim & 7 & 5 & 3 & 14 \\
\hline Christian & 2 & - & - & 9 \\
\hline Other & - & - & - & - \\
\hline \multicolumn{5}{|l|}{ Marital statius } \\
\hline Single & 3 & 1 & - & 8 \\
\hline Married & 6 & 4 & 3 & 15 \\
\hline Widow & - & - & - & - \\
\hline Divorce & - & - & - & - \\
\hline \multicolumn{5}{|l|}{$\begin{array}{l}\text { Educational } \\
\text { status }\end{array}$} \\
\hline Grade $9-10$ & 3 & 4 & - & - \\
\hline Grade $11-12$ & 1 & - & - & - \\
\hline Certificate & - & - & - & - \\
\hline Diploma & 2 & 1 & 3 & 15 \\
\hline Degree & 3 & - & - & 8 \\
\hline Other & - & - & - & - \\
\hline Total & 9 & 5 & 3 & 23 \\
\hline
\end{tabular}


All the 40 key informants confirmed the absence of public toilet in the town in line with the response of households. Forty three percent, $35 \%$ and $23 \%$ of the key informants also added the 
Table 7

Key informants' response regarding latrine and tap water coverage

Variable

Variable

\section{Presence public toile}

Yes

No

\section{Effects of lack of public toilet}

Suffering to use open defection

Health problem related to water born diseases

Environmental pollution

Factors contributing to lack of latrine

Low involvement of administration

Knowledge and attitude related problems

Shortage of income

Lack of enough Land

Lack of follow up

\section{Cosequences of lack of latrine}

Moving out in the dark for defection

women and girls lack safety and privacy

Suffering from bad smell when defecting around home

\section{Factors hindering pure/tapwater coverage}

Shortage of water from the source and lack of tanker

Non-function of public pipe

Low involvement of Administration

Low income of the house holds

Administratiion planned to improve latrine and tapwater coverage

yes

No
No of Respondents $=\mathbf{4 0}$

Male Female Total \% 


\begin{tabular}{|lllll|}
\hline Variable & No of Respondents $=\mathbf{4 0}$ & \\
\hline $\begin{array}{l}\text { Extent to which administration planned to raise latrine and } \\
\text { tapwater coverage }\end{array}$ & 1 & & & \\
\hline $26-50$ & 6 & 1 & 7 & 17.5 \\
\hline $51-80$ & 4 & 1 & 5 & 12.5 \\
\hline 81 \&above & 23 & 4 & 27 & 67.5 \\
\hline No response & & - & 1 \\
\hline
\end{tabular}

existence of open defecation, waterborne health problems and environmental pollution, respectively as the consequence of lack of latrine (Table 7). Most of the key informants pointed out low involvement of administration and residents' awareness/attitude related issues as the main factor that had hidered the residents from building toilets. One third of the key informants had information concerning the adminstration's plan to improve the latrine and tap water coverage of the town.

Forty five percent of the key informants expressed non-functioning of public water pipes (Fig. 5) as a factor for reduced water supply the town. Public pipes were constructed in the town in 2010 at different places, but became non-functional starting from 2013 to the time of investigation. Several key informants also mentioned low involvement of the administration, inadequate amount water from the source and lack of storage tanker as contributing factors to low water coverage of the town.

As a key informant and more concered body, the chief administrator of the town described inadequacy of water as a major limiting factor for the provision of sufficient water to the town. The chief administrator said most of the houses that lacked latrine were built by people living in the surrounding rural areas whom they found difficult to give awareness to avoid open defecation. The presence of plan to build water tanker and public water pipe at different parts of the town to raise its water coverage to about $70 \%$, and to build four public toilets by $2018 / 2019$ was also expressed by the chief administrator of the town.

Observational survey by the investigetors supported the respondents' idea. It was found that most of the households lacked latrine and even the existing latrines were without roofs, hole covers and sewerage system (Figure.2).Shortage of private latrine together with lack of public latrine forced the people to practice open defecation in different places of the town (Figure.3). There were only few private taps with infrequent and insufficient water. More over all public pipes were out of function during the investigation (Fig. 5).These have led the residents to fitch water long waiting line, to transport long distance on their back or by using hourse, or to use impure river water for drinking and other domestic uses

\section{Discussion}

Nearly one third of the households had never attended formal education and $51.6 \%$ of them were at primary level. Over $45 \%$ were farmers. These lower formal educational levels might influence the 
sanitation awareness of the respondents although other sources of knowledge are there. Educational status were significantly associated with use of improved water source and sanitation [8, 2]. Individuals with High school completed or above educational level demonstrated better latrine utilization than those without formal education [12]. Possession of Larger family size ( 5 and above by $40.2 \%$ of the households) could increase the time and energy expend to fetch water and the magnitude of open defecation when latrine and pure water coverage is low as revealed in the current study.

Latrine coverage of the town varied among its zones, being lower in Eastern zone. The overall latrine coverage of the town (45.3\%) was lower than those reported for Dukem town (70.1\%; [18]), Wolaita Sodo town (91\%; [8]), for Ilu Aba Bor Zone (88.2\%; [13]) and the overall Oromia region (72.7\%; [14]) in which Negele town is found. This difference might be due to factors like variation in awareness and economic status of the people among others.

Besides lower coverage, most of the existing latrines (64.5\%) were closer than the minimum recommended distance $(6 \mathrm{~m})$ from a kitchen according to [4]. So, it is easy for bad odour to reach houses and for flies to carry pathogens to the kitchen where food is prepared and kept. Similarly, about $76 \%$ respondents from Nepal indicated latrine distances from their homes were less than $6 \mathrm{~m}$ [15]. The absence of latrine roof (52.3\%), door (53\%) and hole cover (100\%) promotes the invasion and breeding of flies which spread diseases. Moreover, latrines may be filled during rainy seasons and discharged to the environment posing human health and environmental sanitation problems. Lack of cleaning water not only enhances bad odor to reach homes but also hand washing activity after using toilet. Lack of sewerage service had forced the households either to dig new toilets $(70 \%)$ or drain to the environment (30\%) (Table 3) that could lead to economic constraints and environmental pollution. Perception of their latrine as clean, standardized and good for health (by $3.5 \%$ of the households) in the absence of water for cleaning could be due the household's lack of good knowledge of sanitation implying the need to raise public awareness and provide technical assistance in building latrines. In similar study, [16] reported the presence of laterine hole cover in $47.6 \%$ of the latrines in Dembia town, northwestern Ethiopia and [10] reported that $13 \%$ of the respondents were using improved latrine in Chiro Zuria Woreda, eastern Ethiopia

Lack of enough land and money was raised as the main factor that hindered the households from having their own latrine letting them defecate in various sites of the environment including open fields, in bush and house compound as there was no alternative like public toilet. This influences environmental sanitation, human health and psychology [17]. The administration of the town and other concerned bodies should target provision of land, searching for fund and building public toilet to improve the latrine coverage of the town. Moreover, public awareness creation and mobilization should be given due attention as $67 \%$ and $50 \%$ of latrine lacking households expressed that they had no plan and did not get advice, respectively to build latrine. [16] indicated that $88.6 \%$ of the respondents who had latrines were advised to construct latrine by health extension or community health agent personnels in a northwestern Ethiopian town, Dembia. 
The coverage of pure water (7.64\%) of the town was low compared to other towns like Dukem $(98.5 \%$; [18]) and Wolaita Sodo town (68\%; [8]) forcing most of the households to use unprotected Nano River without heat or chemical treatment and to suffer from waterborne diseases. Even [19] reported a 70\% access to improved water of various sources (hand dug well, developed spring and rope pump) for a rural district in western Ethiopia. This shows the need to act immediately by the concerned bodies to expand pure water supply, and create awareness of the community to boil or treat the water using chemicals used to treat water in Ethiopia like "Wuha agar (chlorine-based water treatment solution ) or Bishan gari (aluminum sulphate and calcium hypochlorite),

The responses of the key informants supported that of households regarding lack of public toilet, presence of widespread open defection and its consequences, and shortage of pure water. However, most of the key informants raised low involvement of administration and residents' awareness/attitude related issues in contrast to the households' land and money shortage as major factors for low coverage of latrine.

The key informants enumerated non-functioning public pipes, low involvement of the administration, inadequate amount water from the source and lack of storage tanker as contributing factors to low water coverage of the town. This implies that the water coverage of the town can be partly improved through pipe maintenance, drawing the attention of the town's administration and establish water storage facility.

The administration of the town raised shortage of water from the source and widespread illegal houses as the main factors against pure water and latrine coverage of the town, respectively. It was interesting that the administration of the town had planned to improve pure water coverage to $70 \%$ through establishing water storage tankers and public pipes, and improve latrine coverage via building four public toilets in the town by $2018 / 2019$. However, the administration should also employ reliable alternative water resource like ground water to solve shortage water and achieve the country's target of providingsafe water to $100 \%$ city dwellers by 2020 [20] Moreover, building four public toilets is not expected to solve the toilet shortage of the town so that public awareness creation and mobilization and provision of necessary assistance to build their own toilet should be given due attention.

Observational survey by the investigators supported the households' and key informants' data .It was founded that most of the households lack latrine and even the existing latrines were open to the environment, built from non-durable materials. As the latrines have not been connected to sewerage system, all need to be abandoned once became full leading to land or money constrains, and defecations in the environment. The few available private taps were also featured by infrequent and insufficient water worsening the pure water coverage of the town. Generally, the pure water and latrine coverage of the town was found to much lower than the national Millennium Development Goal (MDG) targeting which targeted a 100\% improved hygiene and sanitation to be achieved by 2015 [21] though the country managed to improve sanitation coverage from just $8 \%$ (1990) to $71 \%(2015)$ and reduce open defecation from 44.3 million (1990) to 28.3 million (2015) [14] 


\section{Conclusions}

Latrine coverage of Negele town was low $(\approx 45 \%)$ due to shortage of land and money, low involvement of administration and residents', and expansion of un-planned illegal houses. Moreover, most of the toilets of the town lacked recommended qualities. Low coverage of private toilets together with the absence of public toilets in the town had led to wide spread open defecation practices with potential and practical negative impact on the health of the community and sanitation of environment. This problem seems to continue in the near future as most toilet lacking households had no plan to construct it and the plan of the administration of the town was insufficient. The pure water (tap water) coverage of Negele town is very low (less than 10\%) due to inadequate water from sources and non-functional existing water taps. The residents could not get pure water within reasonable quantity, time and distance besides living vulnerable to waterborne diseases.

Latrine and pure water coverage of Negele town should be improved via the providing land, supplying loans or searching for aids for the construction of standardized private and public toilets. Searching additional water sources like ground water and maintaining non-functional and/or constructing new water pipe should be promoted to improve the pure water coverage of the town. Plan to solve shortage of latrine and pure water coverage of the town should participate the residents, concerned governmental and non-governmental bodies via continuous awareness creation for better outcomes.

\section{Abbreviations}

UNICEF - United Nation Children's Fund

WHO - World Health Organization

\section{Declarations}

\section{Ethics approval and consent to participate}

The study proposal was reviewed and approved by the ethics review committee of MaddaWalabu University, School of Computational and Natural Sciences. Institutional permission was obtained from Negele town Administrative office before conducting the study. Respondents were given sufficient orientation about the objective of study and the need to participate them. They participated in the study after ensuring their consent orally and they were clearly informed of opt-out consent. Their right to withdraw from the research participation with no objection if they wish was also clearly indicated in the questionnaire. Although, formal/written consent was not taken, the participants were informed of opt-out consent. Relevant individuals encountered during field observation were also informed the purpose of the study and asked for information or taking photos after they ensured their willingness. They were ensured that the information collected would be kept confidential and used only for the research purpose. 


\section{Consent for publication}

Not applicable

\section{Availability of data and materials}

All data generated or analysed during this study are included in this published article and also deposited in Madda Walabu University repository

\section{Competing interests}

The authors declare that they have no any sort of competing interests.

\section{Funding}

The research fund was entirely covered by Madda Walabu University. Madda Walabu University had evaluated and approved the research proposal (research problem, research design, method (s) of data collection and analysis) prepared by the authors. Otherwise, identification of research problem, preparation of study design, collection, analysis, and interpretation of data , and writing the manuscript were performed by the authors alone.No fund was received from any other funding agencies or business or non-profit sectors.

\section{Authors' contributions}

DT identified the research problem, both authors prepared the research design. GD pretested the questionnaire, collected and analyzed data, both authors interpreted the data, wrote and approved the manuscript.

\section{Acknowledgements}

The authors would like to acknowledge Madda Walabu University for funding the study. They also forward their appreciation to all respondents and authorities for their cooperation and providing genuine information.

\section{Authors' information}


${ }^{1}$ earned his BSc degree (Biology), MSc degree (Applied microbiology) and $\mathrm{PhD}$ (Soil and Environmental microbiology) from Addis Ababa. He did the molecular part of his PhD project at James Hutton institute, Scotland, UK. Currently he is an assistant professor serving as lecturer and researcher at Madda Walabu University, College of Natural and Computational Sciences, Department of Biology, P.O.Box 247, Bale Robe , Ethiopia.. ${ }^{2}$ obtained his BSc degree in Biology from Haramaya University and his MSc degree in Biology from Madda Walabu University. He has served and still serving as a teacher at Negele college preparatory school, email: girmadeboch10@gmail.com

\section{References}

1. Tissington K. Basic Sanitation in South Africa. A Guide to Legislation, Policy and Practice SocioEconomic Rights Institute of South Africa (SERI); 2011,

http://www.itldesign.co.za. Accessed 30 May 2018.

2. Tafere $\mathrm{Y}$, Woldie $\mathrm{M}$, Assefa,H. Latrine Coverage and Associated Factors Among Debretabor Town, IJPHS; 2016; 137-141.

3. Ayele T. The Water and Sanitation in Ethiopia; 2017, https://blog.ferrovial.com/en/2017/03/waterand-sanitation-in-ethiopia/, Accessed 30 May 2018.

4. WHO. Simple pit latrines. Fact sheet 3.1 on Environmental sanitation;1996, https://www.google.com/search?sxsrf, Accessed 01 June 2018.

5. WHO. Progress on Safe Treatment and Use of Wastewater. Piloting the monitoring methodology and initial findings for SDG indicator 6.3.1, World Health Organization and UN-Habitat; 2018. https://apps.who.int/iris/handle/10665/275967. License: CC BY-NC-SA 3.0 IGO

6. https://newbusinessethiopia.com/health (Accessed 7 December 2019)

7. Awoke W, Muche S. A cross sectional study: latrine coverage and associated factors among rural communities in the District of Bahir Dar Zuria, Ethiopia, BMC Public Health.

2013; 1-6..

8. Admassie A, Debebe A. Estimating accesses to drinking water supply, sanitation and hygiene facilities in Wolitasodo town, southern Ethiopia, in Reference to National coverage. Journal of Environmental and public Health. 2016; 1- 9

9. Tessema RA(2017) Assessment of the implementation of community-led total sanitation,hygiene, and associated factors in Diretiyara district, Eastern Ethiopia. 2019; PLOS ONE:1 
10. Dagnew GG, Abebaw AF, Wake S L, Derso AG. Assessment of Latrine use and Associated Factors among Rural Community Members in Chiro Zuria Woreda Particularly in Kilinso and Nejebas Kebele. J Microb Biochem Technol 2019; 11: 24-30

11. Naing L, Winn T, Rusli1 BN. Practical issues in calculating the sample size for prevalence studies. Arch Orofac Sci 2006; 1: 9-14

12. Lishager T. Assessment of the implementation of community-led total sanitation, hygiene, and associated factors in Diretiyara district, Eastern Ethiopia. PLOS ONE. 2017; 1-11

13. Oljira D, Berkessa TS. Latrine use and Determinant Factors in Southwest Ethiopia. J Epidemiol Public Health Rev. 2016; 1(6): 2-4.

14. UNICEF. Progress on CLTSH in Ethiopia: Findings from a National Review. WASH Field Note FN/01/2017; Available at https://www.unicef.org/ethiopia/media/176/file/WASH-fieldnote-2017.pdf

15. Budhathoki SS, Shrestha G, Bhattachan M, Singh SB, Jha N, Paras KPK. Latrine coverage and its utilisation in a rural village of Eastern Nepal: a community-based cross-sectional study BMC Res Notes. 2017; 10 (209): 1-7.

16. Yimam YT, Gelaye KA, Chercos DH. Latrine utilization and associated factors among people living in rural areas of Denbia district, Northwest Ethiopia, a cross-sectional study. Pan Afr Med. J.. 2014; 18:334 doi:10.11604/pamj.2014.18.334.4206

17. Prahlad I. Environmental Sanitation "Reflections from Practice" A Module for Community Health Practitioners: society for community health awareness, research and action (SOCHARA) Environmental Sanitation Koramangala, Bangalore; 2015.

18. Mohammed,A.I, Zungu, L. I. and Hoque, M. E. (2013). Access to Safe Drinking Water and Availability of Environmental Sanitation Facilities among Dukem Town Households in Ethiopia. J Hum Ecol, 2014; 41(2): 131-138

19. Kibret FD, Tulu FD. Challenges of Potable Water Supply System in Rural Ethiopia: The Case of Gonji Kolela Woreda, West Gojjam Zone, Ethiopia. Natural Resources and Conservation. 2014; 2(4): 59-69

20. WASH. Water, sanitation and hygiene (WASH); One WASH - the implementation of Ethiopia's National Program Eliminating Trachoma, 2016; https://www.trachomacoalition.org/sites/default/files/content/resources/files/Ethiopia\%20$\% 200$ ne\%20WASH.pdf

21. WHO Africa./Ethiopia Response for Acute Watery Diarrhea outbreak in Moyale town..News Archive, 2016; Available at https://www.afro.who.int/news/ethiopia-response-acute-watery-diarrhea.

22. WHO and UNICEF (2006). Core questions on drinking-water and sanitation for household surveys, Switzerland.

\section{Figures}



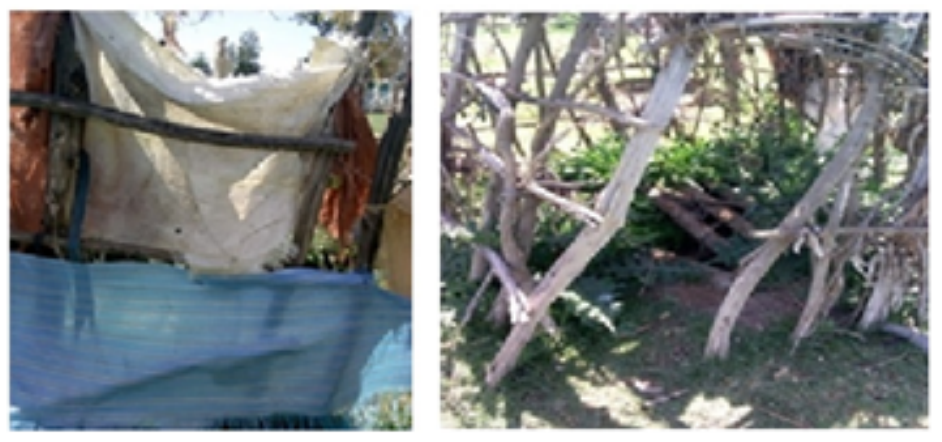

\section{Figure 1}

Appearances of some latrines of the respondents of Negele town in 2018 (Photo by Girma Deboch, 2018).
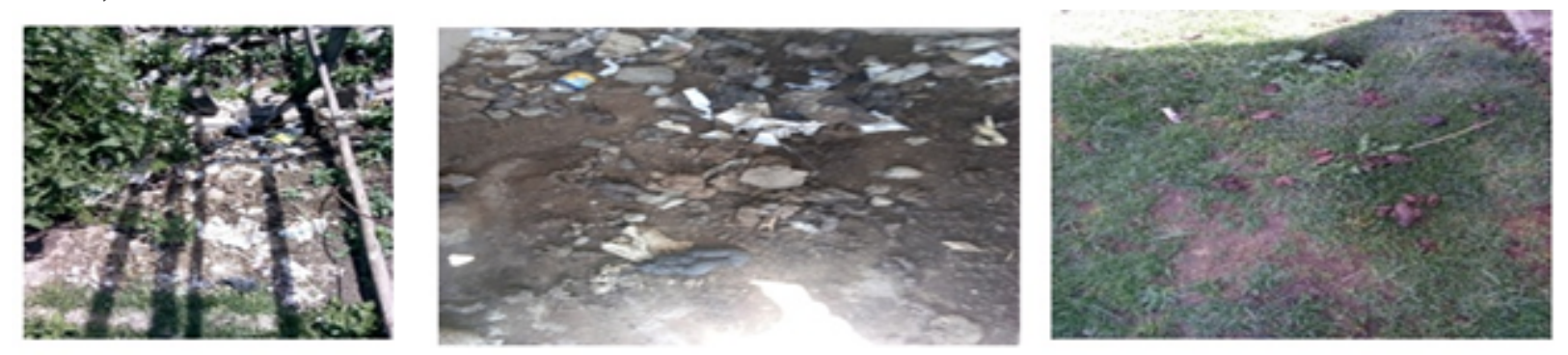

Figure 2

Some open defection sites in Negele town (Photo by Girma Deboch, 2018)
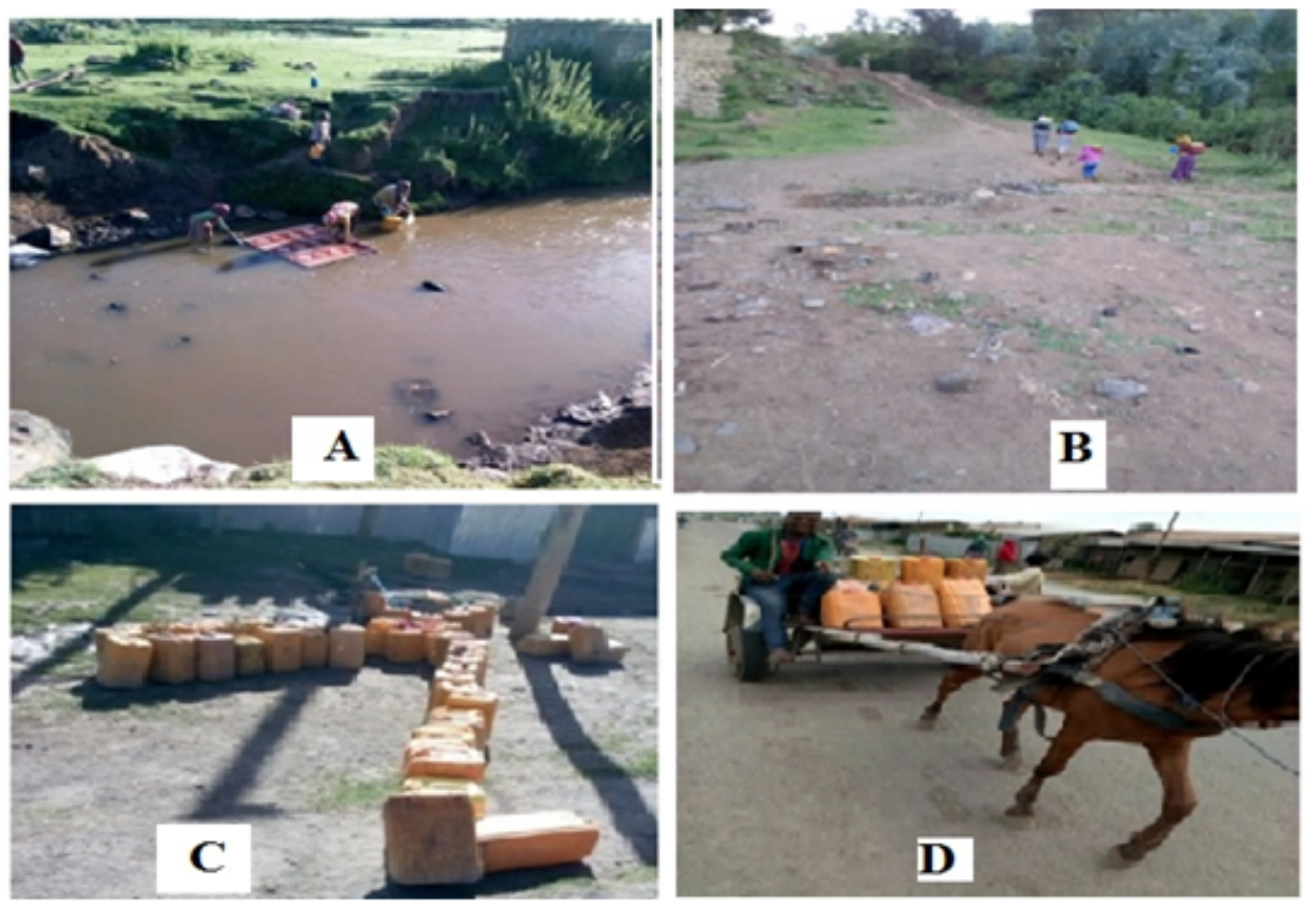

Figure 3 
"Fetching water from Nano River and transporting longer distance on the back of people or using horse $(A, B$ and $D)$ and fetching water from private tap with long waiting line (C) (Photo by Girma Deboch, 2018).

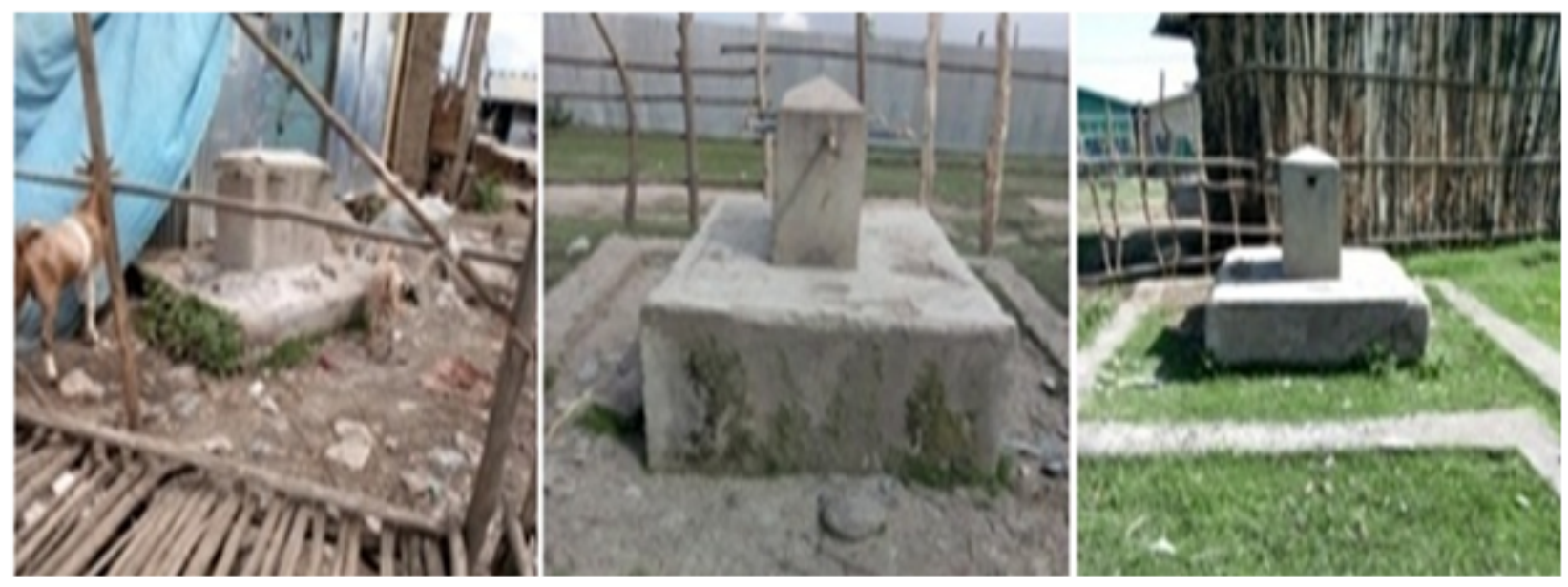

Figure 4

Non- functioning pipes in study area (Photo by Girma Deboch, 2018)

\section{Supplementary Files}

This is a list of supplementary files associated with this preprint. Click to download.

- Supplementaryfiles.docx 